\title{
PARADAN: CULTIVANDO SEMENTES NOS ANOS INICIAIS DO ENSINO FUNDAMENTAL
}

\author{
Renata Morgado Silva ${ }^{1}$ \\ https://orcid.org/0000-0001-7475-0806
}

Soraya de Araújo Feitosa²

https://orcid.org/0000-0002-2876-9335

Jardielly Alencar Vasconcelos Martins ${ }^{3}$

https://orcid.org/0000-0001-6615-1870

RESUMO: Esse artigo apresenta abordagens sobre a cultura indígena roraimense que foram realizadas nos anos iniciais do ensino fundamental do Colégio de Aplicação da Universidade Federal de Roraima - CAp/UFRR que está localizado na capital, Boa Vista. O objetivo central foi ampliar os conhecimentos dos discentes em relação as riquezas culturais dos povos indígenas roraimenses, através de um projeto de extensão intitulado Paradan: cultivando sementes. Partindo de uma realidade concreta, assumiu natureza aplicada. A pesquisa tem abordagem qualitativa e é caracterizada como explicativa. Entre os instrumentos utilizados estão questionários, visita orientada, materiais produzidos pelos discentes e relatórios descritivos. Nos resultados verificouse que abordar a cultura indígena roraimense nos anos iniciais do ensino fundamental ampliou os conhecimentos referente às importantes contribuições para a formação da cultura roraimense e sua identificação no contexto social.

PALAVRAS CHAVE: Anos iniciais do ensino fundamental, Povos indígenas, Valorização cultural.

\footnotetext{
${ }^{1}$ Mestre em Desenvolvimento Regional. Professora. Universidade Federal de Roraima. Boa Vista- RR/Brasil. renata_morgado_@hotmail.com

${ }^{2}$ Mestre em Ensino. Professora. Universidade Federal de Roraima. Boa Vista-RR/Brasil. soraya_feitosa20@ hotmail.com

${ }^{3}$ Mestre em Educação. Professora. Universidade Federal de Roraima. Boa Vista-RR/Brasil. jardi_ef@hotmail. com
}

Rev. Fac. Educ. (Univ. do Estado de Mato Grosso), Vol. 34, Ano 19, № 2, p. 199-219, jul/dez., 2020 (Epub Ahead of Print 15 ago., 2020 ) 


\section{PARADAN: CULTIVATING SEEDS IN THE EARLY YEARS OF ELEMENTARY SCHOOL}

ABSTRACT: This article presents approaches about the Roraima indigenous culture that were conducted in the early years of elementary school of Colégio de Aplicação of the Universidade Federal de Roraima - CAp/UFRR which is located in the capital, Boa Vista. The main goal was to increase the students' knowledge regarding the cultural riches of the Roraima indigenours people, through an extension project entitled Paradan: cultivating seeds. Starting from a concrete reality, it assumed an applied nature. The research has a qualitative approach and it's characterized as explanatory. Among the instruments used are questionnaires, guided visits, materials produced by students and descriptive reports. In the results it was found that addressing about Roraima indigenous culture in the early years of elementary school enlarged the knowledge related to important contributions to the formation of Roraima culture and its identification in the social context.

KEYWORDS: Early years of elementary school, Indigenous peoples, Cultural appreciation.

\section{PARADAN: CULTIVAR SEMILLAS EN LOS PRIMEROS AÑOS DE LA ESCUELA PRIMARIA}

RESUMEN: Este artículo presenta enfoques sobre la cultura indígena roraimense que se llevaron a cabo en los primeros años de la Escuela Primaria del Colegio de aplicación de la Universidad Federal de Roraima - CAp/UFRR que se encuentra en la capital, Boa Vista. El objetivo principal fue ampliar el conocimiento de los estudiantes en relación con las riquezas culturales de los pueblos indígenas de Roraima, a través de un proyecto de extensión titulado Paradan: Cultivating Seeds. Partiendo de una realidad concreta, asumió la naturaleza aplicada. La investigación tiene un enfoque cualitativo y se caracteriza como explicativa. Entre los instrumentos utilizados se encuentran cuestionarios, visitas guiadas, materiales producidos por los estudiantes e informes descriptivos. En los resultados se encontró que abordar la cultura indígena roraimense en los primeros años de educación primaria ampliaba los conocimientos relacionados con importantes contribuciones a la formación de la cultura roraimense y su identificación en el contexto social.

PALABRAS CLAVE: Primeros años de la escuela primaria, Pueblos indígenas, Apreciación cultural. 


\section{Introdução}

Este artigo é um dos resultados do projeto de extensão, intitulado Paradan: cultivando sementes, desenvolvido no Colégio de Aplicação da Universidade Federal de Roraima (CAp/UFRR), e o título "Paradan" foi adotado por ter relação direta com o objetivo do trabalho, trazendo em sua tradução do Wapixana para o português a palavra significa "línguas". O mesmo passou pela análise e aprovação de um professor do CAp/UFRR de etnia Wapixana.

O objetivo do projeto foi ampliar os conhecimentos discentes em relação às riquezas culturais dos povos indígenas roraimenses, para isso foram desenvolvidas diversas atividades interdisciplinares como: pintura corporal, criação de dicionários com palavras indígenas, oficinas, brincadeiras, produção de livros com desenhos e personagens indígenas, entre outras.

Esse tema foi definido não apenas para atender as legislações vigentes, mas por levar em consideração a realidade cultural do Estado de Roraima, onde cerca de $11 \%$ da população se declara indígena. Outra questão relevante no projeto desenvolvido é a quantidade de etnias indígenas e a riqueza cultural existentes em Roraima, único estado brasileiro que está acima da linha do equador.

Desta forma, o trabalho apresenta, inicialmente, um breve contexto histórico, onde são identificadas propostas da Base Nacional Comum Curricular (BNCC) do ensino fundamental e de outros instrumentos legais para trabalhar a história e a cultura indígena nas escolas. Posteriormente, é realizada uma abordagem sobre a importância da interdisciplinaridade em projetos de extensão, espaço em que se estabelece um link com a realidade pesquisada. Em seguida, a metodologia é desenhada com a caracterização da pesquisa, a apresentação das estratégias e instrumentos utilizados no desenvolvimento do estudo.

Ao final, são apresentados os resultados obtidos e as considerações em torno do trabalho desenvolvido.

\section{Cultura indígena e legislação}

A Lei no 11.645 , de 10 de março de 2008, altera o artigo 26-A da Lei no 9.394/96 apontando que nos estabelecimentos de ensino fundamental e médio, públicos e privados, torna-se obrigatório o estudo da História e Cultura Afro-Brasileira e Indígena, e que

O conteúdo programático a que se refere este artigo incluirá 
diversos aspectos da história e da cultura que caracterizam a formação da população brasileira, a partir desses dois grupos étnicos, tais como o estudo da história da África e dos africanos, a luta dos negros e dos povos indígenas no Brasil, a cultura negra e indígena brasileira e o negro e o índio na formação da sociedade nacional, resgatando as suas contribuições nas áreas social, econômica e política, pertinentes à história do Brasil (BRASIL, 2008).

O §4으 do artigo 26 da Lei de Diretrizes e Bases da Educação (lei no 9394/96) enfatiza que "O ensino da História do Brasil levará em conta as contribuições das diferentes culturas e etnias para a formação do povo brasileiro, especialmente das matrizes indígenas, africana e europeia" (BRASIL, 1996, grifo nosso), contemplando o que o caput do artigo descreve, de ter um currículo com uma base nacional comum complementada pela parte diversificada exigida pelas características regionais e locais da sociedade, da cultura, da economia e dos educandos.

A edição da Lei no 11.645 em 2008 fez-se necessária para ampliar o foco dos currículos escolares para a diversidade cultural, racial, social e econômica brasileira, valorizando assim a história e a cultura do povo afrodescendente e indígena, buscando reparar danos à identidade e aos direitos desses povos que se repetem há séculos (BORGES, 2010).

A referida Lei reforça ainda que os conteúdos referentes à história e a cultura afro-brasileira dos povos indígenas brasileiros deverão ser ministrados no âmbito de todo o currículo escolar. Nesse sentido, destaca que a importância de trabalhar essas contribuições nos diferentes componentes escolares é uma forma de promover a valorização dos saberes desses povos e a diversidade cultural no Brasil.

Muito embora exista uma lei que regulamenta a presença desses conteúdos programáticos no currículo escolar, é necessário que a legalidade o torne também legítimo (DOMINGOS JÚNIOR et al, 2017). E torná-lo legítimo pressupõe que a sua presença não se conforme apenas pelo currículo prescrito, mas que seja, principalmente, vivido e real dentro do espaço escolar.

Dialogando com as teorias de currículo, as reflexões acerca do ensino da cultura e da história dos povos indígenas no âmbito escolar, transcende o currículo tradicional, onde não existe o questionamento e que há apenas uma centralidade nas questões técnicas, e perpassa pela conexão do saber, da identidade e do poder enfatizados pelas teorias críticas e pós-críticas do currículo.

Domingos Júnior et al (2017, p. 24) inspirado em Silva (2015) reforça que "Trazer os saberes indígenas para a escola reconhecendo as teorias críticas 
e pós-críticas do currículo, é focar na discussão das causas institucionais, históricas e discursivas que excluem esses saberes da escola" e legalizar e legitimar esses conteúdos nos currículos pressupõe o que Silva (2017, p. 17) afirma permitir "[...] ver a educação de uma nova perspectiva", uma nova forma de realidade, pois a ênfase nos conceitos simplesmente pedagógicos do ensino e aprendizagem são deslocados para os conceitos de ideologia e poder, e ampliado para o conceito de discurso e significação, trazendo discussões sobre gênero, raça, etnia e identidade, tão pertinente ao estudo da cultura indígena.

Mas, apesar da obrigatoriedade no ensino da cultura e história indígenas, a Coordenação Geral da Educação Escolar Indígena (CGEEI) avalia que

[...] há situações diversas pelo país, em relação ao cumprimento da legislação. Em alguns estados, a nova legislação sobre educação escolar indígena contribuiu para muitos avanços, como na criação de programas específicos de formação de professores em magistério nas licenciaturas interculturais, na produção de materiais didáticos específicos, em maior autonomia pedagógica para as escolas indígenas. Em outros, os avanços são poucos e há demora em sua institucionalização (JUNIA, 2019).

É válido ressaltar que a forma de abordagem desses temas depende de um planejamento bem elaborado, isto porque, não se trata de simplesmente falar sobre as culturas afro-brasileira e indígena, mas de aproximar os discentes dos conhecimentos e contribuições desses povos e, nesse processo, permitir-lhes o respeito pela diversidade e a ampliação de saberes.

Aponta-se também que as atividades planejadas permitam a participação ativa dos discentes para que eles possam questionar, dar ideias, expor opiniões e, nesse processo, adquirir e ampliar conhecimentos. Algumas estratégias para inserir a cultura indígena nos componentes curriculares são apontadas pela CGEEI, ligada à Secretaria de Educação Continuada, Alfabetização e Diversidade (SECAD) do MEC:

Nos estudos da língua, por exemplo, pode-se discutir a literatura oral dos povos indígenas e mais recentemente a literatura também escrita. Nos estudos da sociedade, discutir as formas de organização social dos povos indígenas que diferem entre si e entre nossa sociedade. Nos estudos de matemática, apresentar os diferentes sistemas de contagem dos povos indígenas e em que esses sistemas são empregados. Se o projeto for disciplinar, será melhor trabalhar por temática específica para aprofundar o conhecimento (JUNIA, 2019). 
É importante destacar que, assim como apresentar estratégias para se trabalhar a cultura indígena, é preciso investir para que essa inserção aconteça de forma efetiva e em todos os componentes curriculares, que de alguma maneira consigam abarcar o conteúdo e, não apenas nas áreas de conhecimento de história, educação artística e literatura, como sinaliza a lei n¹1.645/08.

A BNCC trouxe algumas orientações acerca desta temática, na sequência destaca-se as disciplinas de Artes e de Educação Física. Para arte, as competências específicas para o ensino fundamental são pontuadas pela Base Nacional Comum Curricular (BNCC):

Explorar, conhecer, fruir e analisar criticamente práticas e produções artísticas e culturais do seu entorno social, dos povos indígenas, das comunidades tradicionais brasileiras e de diversas sociedades, em distintos tempos e espaços, para reconhecer a arte como um fenômeno cultural, histórico, social e sensível a diferentes contextos e dialogar com as diversidades (BNCC, 2019, p. 196).

Nos anos iniciais do ensino fundamental (1ㅇa ao 5 ano) a BNCC aponta como objetivo:

Conhecer e valorizar o patrimônio cultural, material e imaterial, de culturas diversas, em especial a brasileira, incluindo-se suas matrizes indígenas, africanas e europeias, de diferentes épocas, favorecendo a construção de vocabulário e repertório relativos às diferentes linguagens artísticas (BNCC, 2019, p. 201).

Em relação ao componente curricular de Educação física no ensino fundamental, a BNCC aponta a importância de se trabalhar brincadeiras, jogos, danças e lutas de matriz indígena e africana e destaca as seguintes habilidades:

\section{Quadro 1 - Habilidades das Unidades Temáticas: Brincadeiras e Jogos, Danças e Lutas}

Experimentar e fruir brincadeiras e jogos populares do Brasil e do mundo, incluindo aqueles de matriz indígena e africana, e recriá-los, valorizando a importância desse patrimônio histórico cultural. 
Planejar e utilizar estratégias para possibilitar a participação segura de todos os discentes em brincadeiras e jogos populares do Brasil e de matriz indígena e africana.

Descrever, por meio de múltiplas linguagens (corporal, oral, escrita, audiovisual), as brincadeiras e os jogos populares do Brasil e de matriz indígena e africana, explicando suas características e a importância desse patrimônio histórico cultural na preservação das diferentes culturas

Recriar, individual e coletivamente, e experimentar, na escola e fora dela, brincadeiras e jogos populares do Brasil e do mundo, incluindo aqueles de matriz indígena e africana, e demais práticas corporais tematizadas na escola, adequando-as aos espaços públicos disponíveis.

Experimentar, recriar e fruir danças populares do Brasil e do mundo e danças de matriz indígena e africana, valorizando e respeitando os diferentes sentidos e significados dessas danças em suas culturas de origem.

Comparar e identificar os elementos constitutivos comuns e diferentes (ritmo, espaço, gestos) em danças populares do Brasil e do mundo e danças de matriz indígena e africana.

Formular e utilizar estratégias para a execução de elementos constitutivos das danças populares do Brasil e do mundo, e das danças de matriz indígena e africana.

Identificar situações de injustiça e preconceito geradas e/ou presentes no contexto das danças e demais práticas corporais e discutir alternativas para superá-las.

Experimentar, fruir e recriar diferentes lutas presentes no contexto comunitário e regional e lutas de matriz indígena e africana.

Planejar e utilizar estratégias básicas das lutas do contexto comunitário e regional e lutas de matriz indígena e africana experimentadas, respeitando o colega como oponente e as normas de segurança.

Identificar as características das lutas do contexto comunitário e regional e lutas de matriz indígena e africana, reconhecendo as diferenças entre lutas e brigas e entre lutas e as demais práticas corporais.

Fonte: BRASIL, 2018.

Como se percebe, a BNCC aponta vários objetivos para se trabalhar a cultura indígena no Ensino Fundamental, é preciso, entretanto, que o professor 
se disponibilize na utilização de metodologias que vão ao encontro dessas habilidades e, dessa forma, possibilite aos discentes identificar a presença e a sociedade diversificada de culturas indígenas e demais comunidades tradicionais.

\begin{abstract}
Esse processo de aprendizado abre caminhos para práticas de estudo provocadoras e desafiadoras, em situações que estimulem a curiosidade, a reflexão e o protagonismo. Pautadas na observação, nas experiências diretas, no desenvolvimento de variadas formas de expressão, registro e problematização [...] (BNCC, 2019, p. 367).
\end{abstract}

As práticas diferem de acordo com a área de conhecimento, por isso ressalta-se a importância da interdisciplinaridade nesse processo, tópico que será discutido na sequência.

\title{
A ação interdisciplinar através dos projetos de extensão
}

A Universidade é alicerçada pelo tripé ensino, pesquisa e extensão, que são indissociáveis. Aos docentes do Colégio de Aplicação da Universidade Federal de Roraima há a prerrogativa de desempenhar essas três funções. Nesta perspectiva é que se optou por desenvolver o tema deste artigo a partir de um projeto de extensão, pelas especificidades que esse tipo de projeto oportuniza.

De acordo com o conceito desenvolvido pelo Fórum de Pró-Reitores de Extensão das Instituições Públicas de Educação Superior Brasileiras (FORPROEX), apresentado no documento intitulado de Política Nacional de Extensão Universitária, na sua versão 2012, a extensão universitária “[...] é um processo interdisciplinar, educativo, cultural, científico e político que promove a interação transformadora entre Universidade e outros setores da sociedade". É com a comunidade externa que a extensão estreita os laços e mantém um diálogo mais próximo, passa a adotar uma concepção mais educativa e menos assistencialista, onde o objetivo é interligar os diversos saberes estabelecendo links entre a produção do conhecimento com a realidade social, tornando-se parte integrante do currículo (JEZINE, 2004).

A dimensão interdisciplinar e integradora proposta pela extensão, esteve presente fundamentando e consolidando todo o desenvolvimento do projeto "Paradan: cultivando sementes". A essa visão se articula o discurso de Hernández e Ventura (1998, p. 53) quando ressaltam que "[...] a interdisciplinaridade se entende fundamentalmente como a tentativa voluntária de integração de diferentes ciências com objetivos em comum". Um projeto 
de extensão interdisciplinar procura interligar as diferentes ciências, com os saberes produzidos por cada uma, a partir do tema estabelecido. As ligações dos conteúdos com a temática proposta pelo projeto são estabelecidas com as particularidades de cada componente curricular que numa realidade se conectam com seus objetos de conhecimento, validando a importância e o conhecimento unificado do tema no seu campo teórico e prático de atuação.

É importante destacar que o projeto de extensão possibilita integrar a pesquisa na prática docente de forma interdisciplinar, um desafio, considerando que os docentes não possuem o hábito de relacionar sua prática docente com a pesquisa.

Dessa forma, a cultura indígena ao ser trabalhada na perspectiva de um projeto de extensão interdisciplinar se respalda pelo fato de se caracterizar como um tema de interface dentro da educação, onde vem a favorecer as relações de interculturalidade no processo de ensino e aprendizagem e que a convivência escolar entre a cultura indígena e não indígena possa ocorrer de maneira dialógica, numa via de mão dupla, onde há troca, vivência e valorização das práticas educacionais e de respeito a essa cultura e seus saberes. Além disso, as ações de um projeto interdisciplinar transitam com a intencionalidade clara de aproximar os discentes da pesquisa, conhecendo e reconhecendo outras realidades.

De acordo com Costa et al (2015), realizar um projeto interdisciplinar significa eliminar barreiras entre as disciplinas e as pessoas, pois entende-se que o conhecimento é processado em uma rede de conexão e, desta maneira, os profissionais envolvidos buscam se conhecer, trocar experiências e expectativas, contrastando as limitações dos próprios saberes.

Nesse sentido, conhecer a abrangência da cultura local pode favorecer o direcionamento de ações voltadas para a realidade de valorização de cada região, além de propiciar situações de parcerias entre instituições com objetivos comuns ou propostas complementares.

Na sequência, são apresentados alguns dados referentes aos povos indígenas que vivem no estado de Roraima, trazendo também um breve relato sobre a Universidade Federal de Roraima (UFRR), sobre o Instituto Insikiran ${ }^{4}$ de Formação Superior Indígena e sobre o Colégio de Aplicação da Universidade Federal de Roraima (CAp/UFRR), instituições envolvidas no desenvolvimento do projeto de extensão "Paradan: cultivando sementes. "

\footnotetext{
${ }^{4} \mathrm{Na}$ Cultura Macuxi, Insikiran é o nome de um personagem que tinha um irmão chamado Ani'ke e que ambos eram mágicos, sendo Insikiran o mais esperto e proativo. Os próprios indígenas da região contam que existem várias histórias sobre esses dois irmãos.
}

Rev. Fac. Educ. (Univ. do Estado de Mato Grosso), Vol. 34, Ano 19, № 2, p. 199-219, jul/dez., 2020 (Epub Ahead of Print 15 ago., 2020) 
A abrangência indígena no estado de Roraima: Universidade Federal de Roraima, Instituto Insikiran de Formação Superior Indígena e Colégio de Aplicação

Roraima, estado localizado ao extremo norte do Brasil, limitando-se ao norte, noroeste e a oeste com a República Bolivariana da Venezuela; ao norte, nordeste e a leste com a República Cooperativista da Guiana; ao sul e a sudoeste com o estado do Amazonas e a sudeste com o estado do Pará. 0 estado é composto por 15 municípios, sendo Boa Vista a sede política administrativa. Os demais municípios são: Alto Alegre, Iracema, Normandia, Amajari, Bonfim, Pacaraima, Mucajaí, Uiramutã, Caracaraí, Cantá, São Luiz, Rorainópolis, São João da Baliza e Caroebe, ocupando uma área de 225.116,1km² (VALE, 2005; OLIVEIRA, 2003).

De acordo com a contagem populacional realizada em 2010 pelo Instituto Brasileiro de Geografia e Estatística (IBGE), a população do estado de Roraima atinge a marca de aproximadamente 450.479 habitantes, dos quais, 49.637 são de etnias indígenas, totalizando cerca de 11 \% de da população existente (IBGE, 2010).

Entre os municípios e comunidades locais é possível identificar um número superior a 16 etnias distribuídas nas cidades de todo o estado, entre elas estão as etnias: Macuxi; Wapixana; Jaricuna; Taulipáng; Ingarikó; Katuena; Xereu; WaiWai, Tunayana; Sikiyana; Hixkaryana; Karafawyana; Waimiri Atroari; Yanomámi; Mawayána, contando ainda com algumas etnias isoladas, segundo levantamento feito pela Fundação Nacional do Índio (FUNAI, 2019).

A cultura indígena está diretamente ligada a do Estado e deve ser valorizada dentro de cada especificidade, a população pode incentivar e ser incentivada a conhecer as diversas culturas existentes em Roraima, dentre elas, a cultura indígena, "entendendo sua singularidade como princípio fundamental na continuidade deste grupo enquanto povo" (MELO, 2012, p. 36).

A Universidade Federal de Roraima (UFRR) é composta por três Campus:

- Campus Murupu ${ }^{5}$ : que forma técnicos agrícolas, e abriga a Escola Agrotécnica (EAgro), voltada à comunidade rural do Estado e oferecendo também o curso de Agroecologia em nível superior;

- Campus Cauamé ${ }^{6}$ que abriga o Centro de Ciências Agrárias (CCA),

\footnotetext{
${ }^{5}$ Murupu, literalmente, refere-se a duas palavras: Mu'ru e Pu, onde Mu'ru significa tatu bola e Pu significa pé. Dessa forma, a tradução para o português é 'pé de tatu bola'. De acordo com os indígenas de Etnia Macuxi, nessa região existiam muitos tatus bola.

${ }^{6}$ Cauã-mé é de origem tupi-guarani e significa rio dos gaviões.
} 
com os cursos de Agronomia, Medicina Veterinária e Zootecnia, além dos Departamentos de Solos e Engenharia Agrícola e de Fitotecnia, com cursos de Mestrado e Doutorado em Agronomia;

- Campus Paricarana ${ }^{7}$ : onde funcionam a Reitoria e Pró-reitorias, Biblioteca Central, Controle e Registro Acadêmicos, 11 dos 12 Centros didáticos, Institutos, Núcleos e Unidades de pesquisa, o restaurante e a residência universitária (UFRR, 2015).

No Campus Paricarana, funciona ainda o Instituto Insikiran de Formação Superior Indígena, para atender a demanda dos povos indígenas de Roraima, representados por suas organizações, com o objetivo de viabilizar a formação profissional, de modo específico, diferenciado e intercultural, oferecendo três cursos de formação superior para indígenas em nível de graduação: a Licenciatura Intercultural, criada em 2001, o Bacharelado em Gestão Territorial Indígena, criado em 2009, e o curso de Bacharelado de Gestão em Saúde Coletiva Indígena, criado em 2012 (UFRR, 2019a).

O Colégio de Aplicação da Universidade Federal de Roraima (CAp/ UFRR) também faz parte do Campus Paricarana e atende aproximadamente 480 discentes distribuídos em uma turma de 1으, 2으, 3우 4으 e 5음 ano (anos iniciais do Ensino Fundamental), e duas turmas 6우 7으, 8으 e 9음 (anos finais do Ensino Fundamental) e de Ensino Médio de 1으, 2으 e 3음 ano. O CAp/UFRR conta ainda com cerca de 65 docentes, com formações em Pedagogia, Educação Física, Português, Matemática, Física, Química, Espanhol, Inglês, Artes, Música, Biologia, Informática, História e Geografia (UFRR, 2019b). O Colégio possui discentes e docentes de diversas etnias indígenas.

Nesse sentido, compreende-se que a história de Roraima, entrelaçasse com as histórias dos povos indígenas. Portanto, é essencial que desde cedo, qualquer cidadão possa vivenciar momentos de aprendizagem que levem em conta as particularidades da formação da população roraimense. Dessa forma, o projeto de extensão desenvolvido visou possibilitar momentos de discussão e reflexão acerca do indígena na sociedade em que estamos inseridos, compreendendo a formação da identidade de cada indivíduo.

Com tantos novos costumes, gostos, opções e conhecimentos, verifica-se que a cultura vai sendo construída continuamente, não é fixa ou inviolável, é um processo constante de complementação, modificação no qual os indivíduos vão interagindo entre si, trocando ideias, partilhando crenças,

\footnotetext{
${ }^{7}$ A palavra Paricarana refere-se a uma árvore cuja a casca é áspera e grossa. A tradução do Macuxi para o português é ríspida.
}

Rev. Fac. Educ. (Univ. do Estado de Mato Grosso), Vol. 34, Ano 19, № 2, p. 199-219, jul/dez., 2020 (Epub Ahead of Print 15 ago., 2020) 
formando e discutindo opiniões. E a partir dessa junção com novos conhecimentos, constroem uma nova história de vida, na qual os hábitos e costumes, sentimentos, expressões, gostos, gêneros, tradições e costumes locais vão se inserindo e compondo um novo panorama cultural (NASCIMENTO, 2014).

Estabelecendo um reconhecimento de outras culturas, no caso indígenas, através da valorização desenvolvida ao longo do projeto, contribuindo, assim, para o processo de formação cidadã. O tema "Paradan: cultivando sementes" articula presente e passado dos indígenas em Roraima, através de sua cultura expressa na literatura, nos jogos e na arte, assim como outros elementos pertinentes ao debate do tema.

O projeto foi uma iniciativa do corpo docente do Colégio de Aplicação, com o objetivo de valorizar a cultura indígena, presente no estado, componente do currículo escolar que congregou um conjunto de ações articulando com ensino, pesquisa e extensão, tanto com relação aos trabalhos desenvolvidos, como também para o levantamento de necessidades quanto à compreensão da discussão do tema.

A realização do projeto aconteceu ao longo do segundo bimestre de 2019, com a finalidade primordial de propiciar o envolvimento dos discentes nas discussões, organização e desenvolvimento das atividades, com a intenção da apreciação histórica, social, política e cultural sobre os indígenas em Roraima. O delineamento metodológico é apresentado na sequência como forma de explicitar o percurso do projeto de extensão.

\section{Desenho metodológico}

Esta pesquisa foi realizada no Colégio de Aplicação da Universidade Federal de Roraima e seu objetivo geral foi ampliar os conhecimentos dos discentes em relação às riquezas culturais dos povos indígenas roraimenses. O grupo de sujeitos é constituído por cerca de 130 discentes dos anos iniciais do ensino fundamental.

A pesquisa desenvolvida partiu de uma realidade concreta, assumindo natureza aplicada e caracterizou-se como explicativa de abordagem qualitativa (SAMPIERI, COLLADO e LUCIO, 2012).

O projeto suscitou reflexões advindas da teoria da História Social, dos estudos culturais e de outras áreas das ciências, com interdisciplinaridade, como subsídio para o desenvolvimento do projeto junto aos docentes e discentes.

No processo de construção do projeto a primeira etapa realizada foi 
no tocante ao diagnóstico foi realizado por meio de questionário semiaberto composto por quatro questões, para identificar o que os discentes conheciam frente a temática que seria trabalhada e qual sua percepção quanto a cultura indígena, aplicado aos discentes do $1^{\circ}$ ao 5 o ano do Ensino Fundamental conforme a figura seguinte:

Figura 1 - Teste diagnóstico.

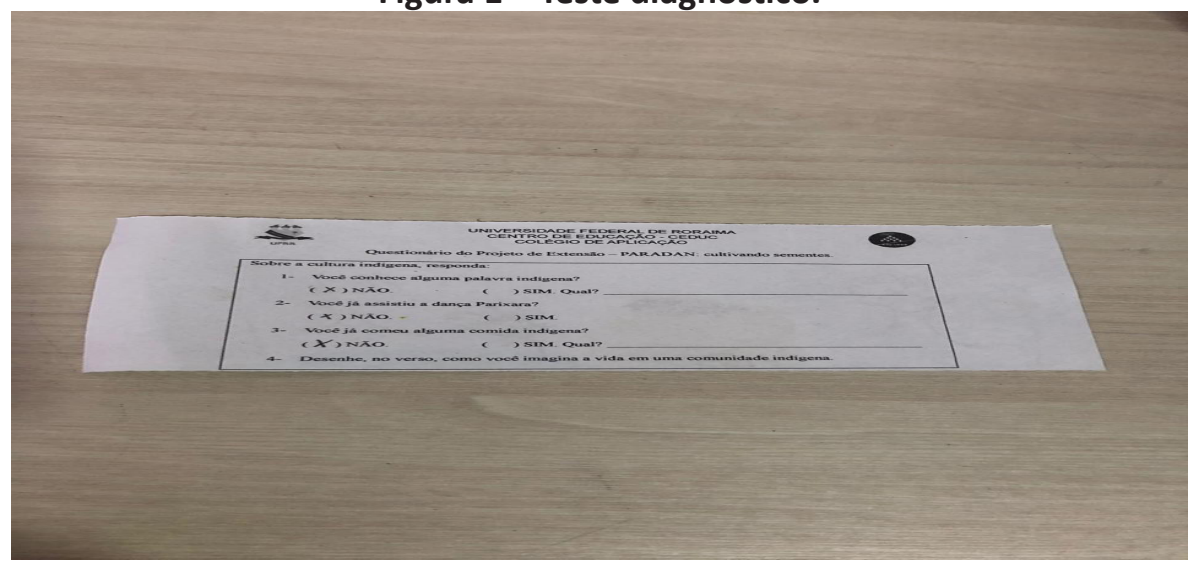

Fonte: Renata Morgado Silva (2019).

Com relação a dimensão teórica e metodológica arrolou-se a discussão em sala de aula sobre o tema, por meio de leituras de literaturas indígenas, da contribuição da língua indígena para o português brasileiro, da cultura e figura indígena na literatura e dos jogos e brincadeiras indígenas.

Na figura 2 é possível perceber os discentes explorando os espaços do Instituto Insikiran, conhecendo as salas de aula, o auditório, a horta, o tapiri ${ }^{8}$ e acompanhando algumas atividades realizadas no referido bloco da UFRR. Através da visita guiada por discentes indígenas, as crianças conheceram como funciona a graduação, quais cursos a UFRR oferece especificamente para o público indígena e os espaços destinados para as atividades.

\footnotetext{
${ }^{8}$ Tapiri é uma pequena casa (casinha) que serve de abrigo da chuva. Fonologicamente, Tapi, é o som do pingo (gota) d'água da chuva.
} 
Figura 2 - Atividade de visita guiada ao Bloco Insikiran/UFRR: 2019.
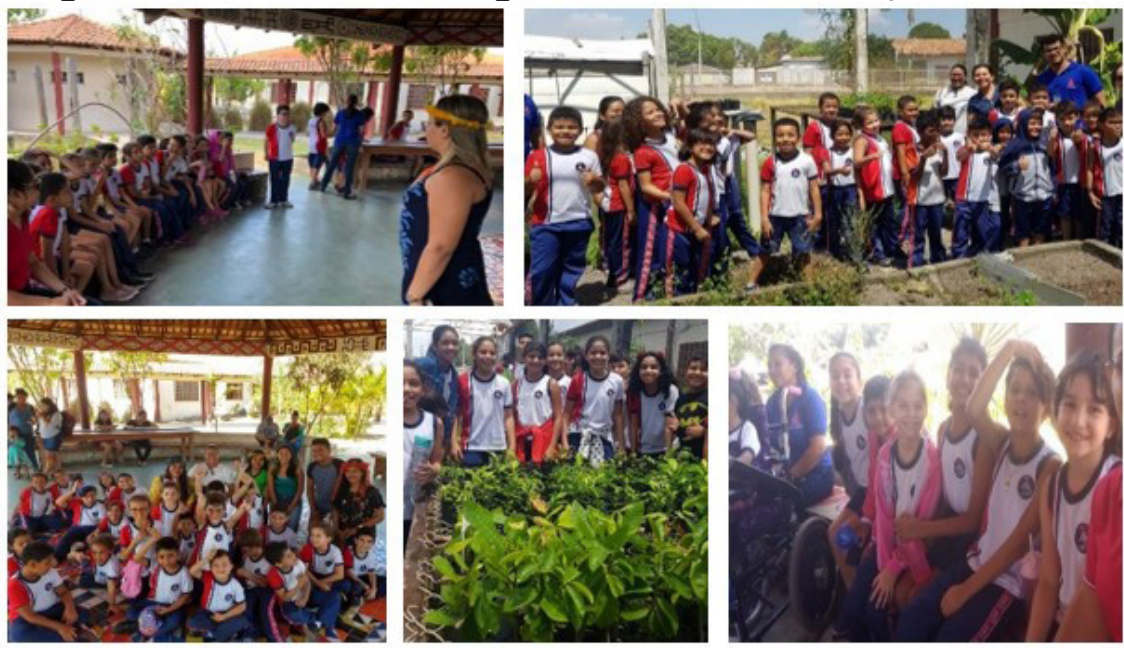

Fonte: Fotos cedidas pelas professoras do $1^{\circ}$ ao $5^{\circ}$ ano do Ensino Fundamental do CAp/UFRR, ano letivo 2019.

A Dança Parixara ${ }^{9}$ faz parte da cultura indígena e está presente em diversas etnias, ela é utilizada nas comemorações dos povos indígenas. A figura 3 mostra aproximadamente 128 discentes do CAp/UFRR participando de uma apresentação e posteriormente de uma oficina da dança, conduzida por indígenas, discentes do curso de Graduação oferecido pelo Instituto Insikiran.

Figura 3 - Apresentação e oficina da dança Parixara.
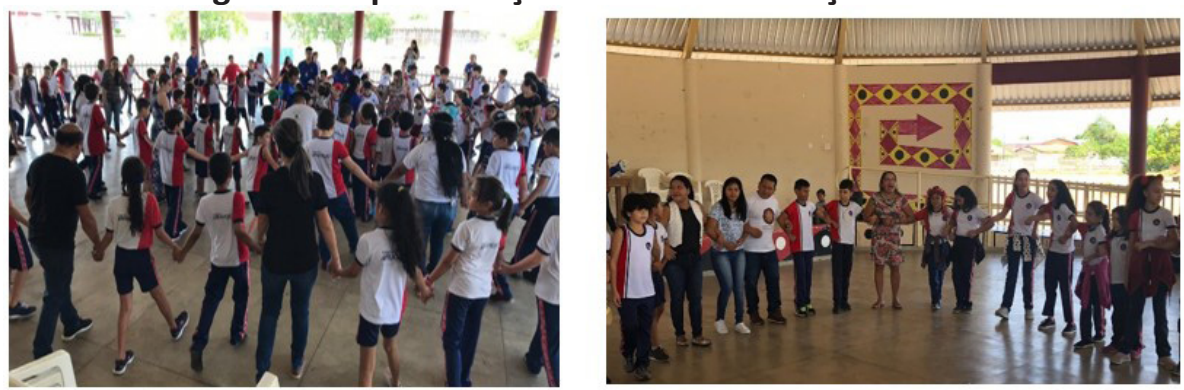

Fonte: Fotos cedidas pelas professoras do 1음 ao 5 ano do Ensino Fundamental do CAp/UFRR, ano letivo 2019.

\footnotetext{
${ }^{9} \mathrm{Na}$ Cultura Macuxi, Perisara é a grafia correta da palavra e refere-se a uma das danças feitas em datas comemorativas, como: boa colheita de safra, boa caçada, boa pesca.
} 
Com a perspectiva de propiciar a interação, os discentes indígenas ofereceram, no âmbito do Colégio de Aplicação da UFRR, oficinas de pintura corporal e das línguas Ingarikó, Wapixana, Macuxi e Ye'kuana. Na oportunidade os discentes fizeram perguntas sobre a cultura indígena de cada etnia e puderam perceber a participação dos indígenas das diversas áreas da sociedade. A figura 4 elucida as oficinas desenvolvidas em sala. Essas oficinas foram conduzidas por indígenas, alunos do Instituto Insikiran.

Figura 4 - Oficinas de línguas e pintura corporal.
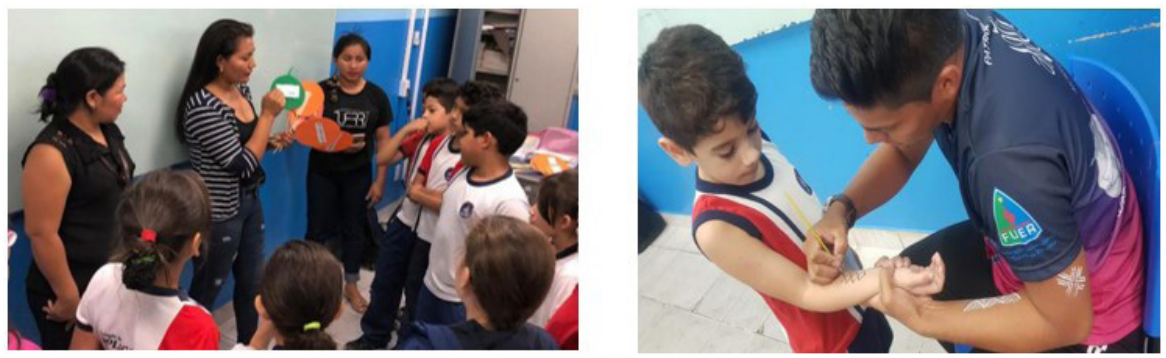

Fonte: Fotos cedidas pelas professoras do 1ㅇ ao 5으 ano do Ensino Fundamental do CAp/UFRR, ano letivo 2019.

Durante o segundo bimestre as turmas do 10 ao 50 participaram de atividades que envolveram a cultura indígena. Na disciplina de Educação Física, por exemplo, os discentes conheceram jogos e brincadeiras indígenas. Nas outras disciplinas foram desenvolvidas atividades diferenciadas. 010 ano do ensino fundamental trabalhou as lendas indígenas produzidas em Roraima, 0 2ㅇ ano fez um estudo sobre cultura indígena através da literatura, o 3ㅇabordou a contribuição da língua indígena para o português brasileiro, o 4ํ produziu desenhos e histórias indígenas que culminaram em um livro de histórias de heróis e heroínas indígenas, e o 5 ㅇ ano trabalhou as figuras indígenas na literatura. 
Figura 5 - Atividades desenvolvidas durante o segundo bimestre, nas disciplinas de Português, Matemática, Artes, Educação Física, História, Geografia e Ciências.
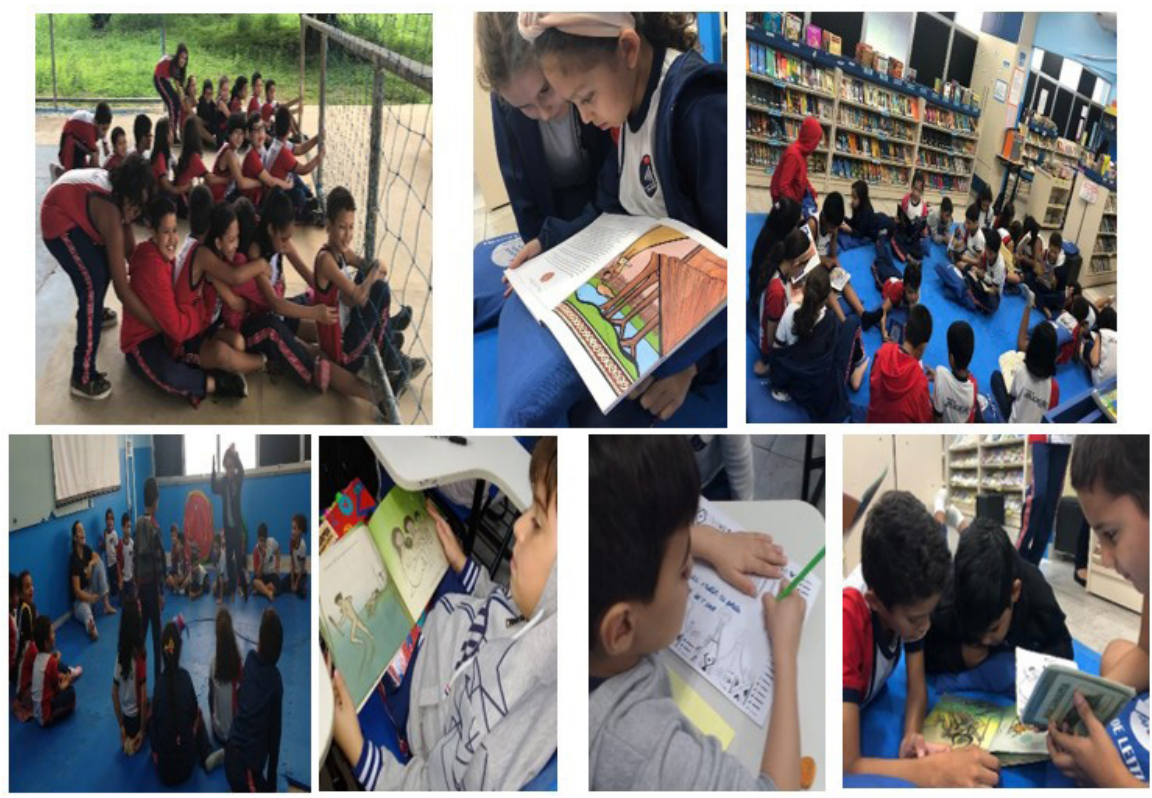

Fonte: Fotos cedidas pelas professoras do 1으 ao 5으 ano do Ensino Fundamental do CAp/UFRR, ano letivo 2019.

Para finalizar as atividades do projeto, os trabalhos produzidos foram expostos para apreciação e avaliação dos próprios discentes, onde tanto a comunidade escolar como a familiar foram convidadas a prestigiar as atividades, com a finalidade de fomentar a discussão e com o intuito de construir um processo de ressignificação da história dos indígenas em Roraima. 


\section{Figura 6 - Exposição dos trabalhos desenvolvidos pelos discentes do 10 ao}

5으. ano.
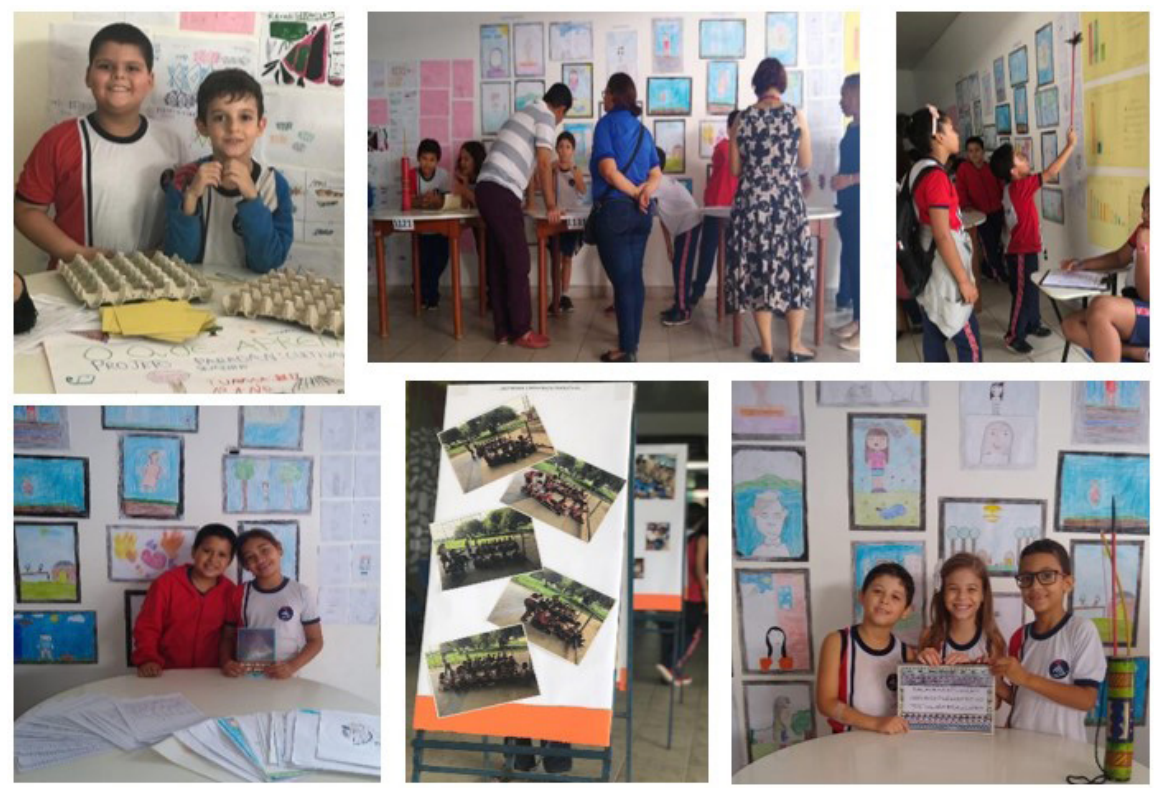

Fonte: Fotos cedidas pelas professoras do 1을 ao 5 ano do Ensino Fundamental do CAp/UFRR, ano letivo 2019.

Após a conclusão do projeto foi aplicado o mesmo questionário para identificar se a aprendizagem havia sido significativa. Os questionários foram aplicados pelos professores envolvidos no projeto, cada aluno em sua sala de aula, os professores explicaram o objetivo do questionário e do projeto que os alunos iriam participar.

\section{Resultados e discussão}

O Projeto foi desenvolvido com os alunos dos anos iniciais do Ensino Fundamental, abarcando cerca de 130 discentes do 10 ao 50 ano do Ensino Fundamental do Colégio de Aplicação, discentes indígenas dos cursos de graduação do Instituto Insikiran, além de contar com a participação e apoio de 13 docentes do CAp/UFRR, todos docentes dos anos iniciais do Ensino Fundamental.

O questionário, aplicado antes do desenvolvimento das atividades, 
foi respondido por 91 alunos das turmas de 10 ao 5 을 ano para que fosse investigado o nível de conhecimentos acerca do tema trabalhado. Como resultado foi possível perceber que mais de $90 \%$ dos discentes garantiram não conhecer nenhuma palavra indígena, $81 \%$ dos alunos informaram que nunca haviam assistido a uma apresentação de dança Parixara e quase 65\% alegaram não ter degustado nenhuma comida indígena.

No decorrer das atividades os alunos descobriram novas palavras, jogos diferentes, aprenderam o significado da pintura corporal nas comunidades indígenas e perceberam que existe um bloco na universidade exclusivo para atender a demanda do público indígena.

As atividades realizadas permitiram aos discentes entenderem a proximidade e influência da cultura indígena no dia-a-dia de todos, identificando palavras, comidas e hábitos advindos da miscigenação existente no estado de Roraima, que moldam a cultura local e entrelaçada a cultura roraimense, mostra que os indígenas exercem papel fundamental na construção da história local.

O questionário foi aplicado novamente depois da culminância do Projeto "Paradan: cultivando sementes" para que fosse possível identificar o quanto as atividades haviam sido significativas. Nas respostas, $77 \%$ afirmaram agora conhecerem palavras indígenas, cerca de $85 \%$ declararam já terem assistido a uma apresentação de dança Parixara e $85 \%$ informaram já ter degustado uma comida indígena.

Os números mostram uma quantidade relevante de alunos que conseguiram extrair das ações do Projeto, informações básicas que podem estimular futuras percepções frente a valorização da cultura indígena. Por outro lado, a pesquisa mostra a necessidade de continuidade do Projeto para que as experiências frente ao tema trabalhado possam incluir cada vez mais discentes.

\section{Considerações finais}

Durante as atividades desenvolvidas no projeto, foi possível observar a percepção dos discentes frente a temática trabalhada e a oportunidade de ampliação do conhecimento estudantil diante das especificidades e costumes indígenas.

Buscar alternativas para realizar ações que envolvam temáticas indígenas, pode auxiliar a valorização cultural e o respeito às diferenças, além de favorecer uma aprendizagem com significados aos discentes que tem em sua cultura, total influência indígena e em determinadas situações desconhecem as proximidades culturais, fruto da miscigenação, característica bastante latente 
no Brasil. Em Roraima, por toda sua construção histórica e por se tratar de uma cidade fronteiriça, tal miscigenação ganha ainda mais força.

A escola precisa adotar ações que favoreçam a valorização cultural, uma vez que tem responsabilidade com a formação social dos alunos. É importante que os agentes envolvidos no processo educacional (docentes, pais, coordenadores pedagógicos, técnicos educacionais) percebam a cultura indígena como parte da cultura de Roraima e do Brasil e passem a trabalhar a temática em todos os segmentos da Educação Básica.

Desta forma, a importância de se trabalhar a cultura indígena com os discentes está muito mais que atender a uma questão legal, mas principalmente possibilitar o conhecimento e o respeito aos saberes desses povos que muito contribuíram e contribuem para o desenvolvimento social e cultural do nosso país.

Com base em toda a discussão já realizada neste projeto, e considerando suas contribuições para a ação formativa de discentes e docentes, este trabalho pode ser utilizado como modelo em outros contextos, desde de que favoreça as adaptações necessárias a cada espaço onde a pesquisa for realizada. Da mesma forma, ressalta-se a importância desse projeto de extensão no que diz respeito à formação intercultural e à apropriação de novos saberes.

\section{Referências}

BRASIL. Lei no 9394, de 20 de dezembro de 1996. Estabelece as diretrizes e bases da educação nacional. Disponível em: <http://www.planalto.gov.br/ ccivil_03/LEIS/L9394.htm> Acesso em: 08 jul. 2019.

BRASIL Lei $n^{\circ}$ 11.465/08 de 10 de março de 2008. Estabelece a obrigatoriedade da temática "História e Cultura Afro-Brasileira e Indígena". Diário Oficial da União - Seção 1 -11/3/2008, p. 1.

BRASIL Ministério da Educação. Base Nacional Comum Curricular-BNCC. Brasília, DF, 2018.

BRASIL FUNDAÇÃO NACIONAL DO ÍNDIO. Índios no Brasil. Terras Indígenas. Disponível em: <http://www.funai.gov.br/index.php/indios-no-brasil/terras-indigenas> Acesso em: 07 jul. 2010.

BRASIL População do estado de Roraima (Censo demográfico 2010). Disponível em: <https://censo2010.ibge.gov.br/sinopse/index.php?uf=14> Acesso em: 07 jul. 2010. 
BORGES, Elisabeth Maria de Fátima. A Inclusão da História e da Cultura Afro-brasileira e Indígena nos Currículos da Educação Básica. Revista Mestrado em História, v. 12, n. 1, jan./jun. Vassouras: 2010, p. 71-83. Disponível em: <https://www2.olimpiadadehistoria.com.br/vw/1IN8I5YjrMDY_MDA_ 606d5_/05A_Inclusaodahistoriaculturaafro.pdf> Acesso em: 10 jul $20 \overline{1} 9$.

COSTA, Ana Valéria de Figueiredo; DUARTE, Ilda Maria Baldanza Nazareth; COSTA, Agenor Pereira. A interdisciplinaridade na gestão de projetos: "contextualizando as grandes áreas do conhecimento" na formação de professores. In: EDUCERE. XII CONGRESSO NACIONAL DE EDUCAÇÃO. 2015, Paraná. Anais...Paraná, 2015, p. 16696-16706.

DOMINGOS JÚNIOR, et al. Corpo, cultura de movimento e jogos indígenas nas aulas de educação física. Cadernos de Formação RBCE, p. 21-32, mar. 2017. Disponível em: <http://revista.cbce.org.br/index.php/cadernos/article/view/2231> Acesso em: 30 jun 2019.

FÓRUM DE PRÓ-REITORES DE EXTENSÃO DAS UNIVERSIDADES PÚBLICAS BRASILEIRAS. Plano Nacional de Extensão Universitária. Ilhéus: Editus, 2001. (Coleção Extensão Universitária; v.1)

FÓRUM DE PRÓ-REITORES DE EXTENSÃO DAS UNIVERSIDADES PÚBLICAS BRASILEIRAS. Política Nacional de Extensão Universitária. Manaus: maio 2012. Disponível em: <http://proex.ufsc.br/files/2016/04/Pol\%C3\%ADtica-Nacional-de-Extens\%C3\%A3o-Universit\%C3\%A1ria-e-book.pdf>. Acesso em: 08 jul 2019.

HERNÁNDEZ, Fernando; VENTURA, Montserrat. A organização do currículo por projetos de trabalho: O conhecimento é um caleidoscópio. Porto Alegre: ARTMED, 1998. p. 198.

JEZINE, E. As Práticas Curriculares e a Extensão Universitária. In: 2 Congresso Brasileiro de Extensão Universitária, 2004, Belo Horizonte/MG. Anais do 2은 Congresso Brasileiro de Extensão Universitária, 2004. Disponível em: <https:// www.ufmg.br/congrext/Gestao/Gestao12.pdf>. Acesso em: 12 jul 2019.

JUNIA, Raquel. História e cultura africana e indígena nas escolas. Disponível em: <http://www.epsjv.fiocruz.br/noticias/reportagem/historia-e-cultura-africana-e-indigena-nas-escolas> Acesso em: 10 mar. 2019.

MELO, Luciana Marinho de. Fluxos Culturais e os Povos da Cidade: entre os Macuxi e Wapichana de Boa Vista - Roraima. Rio de Janeiro: Instituto do Patrimônio Histórico e Artístico Nacional, 2012, 156 p.

NASCIMENTO, Cleo Amorim. Subjetividade e Identidade na poesia topofili- 
ca de Zeca Preto - Boa Vista, 2014. Disponível em:<http://www.bdtd.ufrr.br/ tde_arquivos/5/TDE-2014-05-02T112541Z-136/Publico/CleoAmorimNascimento.pdf>. Acesso em: 17 jul. 2019.

OLIVEIRA, Reginaldo Gomes. A herança dos descaminhos na formação do Estado de Roraima. 378p. Tese (Doutorado) - Universidade de São Paulo, São Paulo, 2003.

Disponível em: <file://C:/Users/ufrr/Downloads/A\%20Heran_\%20dos\%20 descaminhos\%20da\%20forma_o\%20do\%20estado\%20de\%20Roraima.pdf > Acesso em: 21 jun. 2019.

SAMPIERI, Roberto Hernández; COLLADO, Carlos Fernández; LUCIO, Pilar Baptista. Metodologia de pesquisa. - 3.ed. - reimpr. - São Paulo: McGraw-Hill, 2012.

SILVA, Tomaz. Tadeu. Documentos de Identidade: uma introdução às teorias do currículo. 3o edição. 9으 reimpressão. Belo Horizonte: Autêntica, 2017.

UFRR. UNIVERSIDADE FEDERAL DE RORAIMA. Ensino. Escolas / Institutos / Núcleos. Apresentação da Universidade Federal de Roraima. Boa Vista (RR): UFRR, 2015. Disponível em: <http:// ufrr.br/a-ufrr>. Acesso em: 09 jul. 2019.

UFRR UNIVERSIDADE FEDERAL DE RORAIMA. Ensino. Escolas / Institutos / Núcleos. Apresentação do Instituto Insikiran de Formação Superior Indígena. Universidade Federal de Roraima. Boa Vista (RR): UFRR, 2019. Disponível em: $<$ http://ufr.br/insikiran/index.php?option=com_content\&view=article\&id=60\&ltemid=268>. Acesso em: 09 jul. 2019.

UFRR UNIVERSIDADE FEDERAL DE RORAIMA. Ensino. Escolas / Institutos / Núcleos. Histórico do Colégio de Aplicação - CAp. Boa Vista (RR): UFRR, 2019. Disponível em: <http://ufrr.br/cap/index.php/apresentacao>. Acesso em: 09 jul. 2019.

VALE, Ana Lia Farias. O "Ceará" em Roraima: migração de cearense 19801999. Jaboticabal: FUNEP, 2005, 173 p.

Data de recebimento: 26.09 .2019

Data de aceite: 20.09 .2020 